\title{
Biology of Plasmodium falciparum gametocyte sex ratio and implications in malaria parasite transmission
}

\author{
Noëlie Béré Henry', Samuel Sindié Sermé1, Giulia Siciliano², Salif Sombié1, Amidou Diarra ', N'fale Sagnon',
} Alfred S. Traoré ${ }^{3}$, Sodiomon Bienvenu Sirima ${ }^{1,4}$, Issiaka Soulama ${ }^{1 *}\left(10\right.$ and Pietro Alano ${ }^{2^{*}}$

\begin{abstract}
While significant advances have been made in understanding Plasmodium falciparum gametocyte biology and its relationship with malaria parasite transmission, the gametocyte sex ratio contribution to this process still remains a relevant research question. The present review discusses the biology of sex determination in $P$. falciparum, the underlying host and parasite factors, the sex specific susceptibility to drugs, the effect of sex ratio dynamics on malaria parasite transmission and the development of gametocyte sex specific diagnosis tools. Despite the inherent differences across several studies and approaches, the emerging picture highlights a potentially relevant contribution of the $P$. falciparum gametocyte sex ratio in the modulation of malaria parasite transmission. The increasing availability of molecular methods to measure gametocyte sex ratio will enable evaluation of important parameters, such as the impact of drug treatment on gametocyte sex ratio in vitro and in vivo as well as the changes of gametocyte sex ratios in natural infections, key steps towards elucidating how these parameters affect parasite infectiousness to the mosquito vectors.
\end{abstract}

Keywords: Malaria, Plasmodium falciparum, Gametocyte, Transmission, Sex ratio, Antimalarial drugs

\section{Background}

Despite the recent public health effort, malaria remains one of the leading causes of death worldwide [1]. In the global effort aiming at disease elimination and marked by the use of effective anti-malarial drugs and insecticide-treated nets (ITNs), the Plasmodium gametocytes deserve a special attention, being the parasite blood stages responsible for human to mosquito parasite transmission [2]. Developing effective strategies to control malaria disease and block parasite transmission requires further understanding of the genetic determinants governing the parasite life cycle between vertebrate human hosts and female Anopheles mosquito vectors.

\footnotetext{
*Correspondence: soulamacnrfp@gmail.com; pietro.alano@iss.it ${ }^{1}$ Centre National de Recherche et de Formation sur le Paludisme, Ouagadougou, Burkina Faso

${ }^{2}$ Dipartimento di Malattie Infettive, Istituto Superiore di Sanità, Rome, Italy

Full list of author information is available at the end of the article
}

In the human host, a fraction of Plasmodium falciparum blood asexual stage produces sexual stages, male and female gametocytes. In this parasite, gametocytogenesis requires a comparatively more extended period (8-12 days) than in other human malaria parasite species $[3,4]$, in which five stages (I to V) of morphological development are routinely classified [5]. Gametocyte stages I to IV were reported to sequester in deep organs (bone marrow and spleen) while stage $\mathrm{V}$ gametocytes are found in the peripheral blood [6] where they take an additional 3 days to become infectious to mosquitoes [710]. Malaria parasite transmission requires the presence of both sexes of gametocytes for fertilization, eventually producing new parasite stages (the sporozoites) where genetic recombination has occurred and determines the genetic make-up of the parasite offspring [11].

During malaria infections, $P$. falciparum the rate of gametocyte production is influenced by several factors, both from the human host $[4,11]$ (haemoglobin level [12-14], host immunity [15, 16], anti-malarial drug 
treatment [17-19]) and from the parasite (genetic diversity of infection [20] or mixed infection [21,22], asexual stage densities [23]). In several cases these studies have not concomitantly investigated whether and how these factors also modified the gametocyte sex ratio, which is defined as the ratio of the number of male gametocytes over female gametocytes and which is typically female biased in Plasmodium parasites [24]. Evidence of factors influencing the gametocyte sex ratio derives from controlled infections mainly on rodent parasites and from a few studies of $P$. falciparum natural infections or clinical trials.

The impact of anaemia on gametocyte sex ratio was experimentally shown in rodent and avian Plasmodium parasites [25-28] and in studies on P. falciparum infected children [14, 29]. A role of immunity was documented in P. falciparum infected children [30], whereas a modified gametocyte sex ratios was described upon drug treatment of $P$. falciparum infections [31,32].

In vitro assays on $P$. falciparum gametocytes suggested that male gametocytes are more vulnerable to anti-malarial drugs than female gametocytes [33]. This effect has been recently investigated in vivo in clinical trials assessing the effect of combination drug treatments including primaquine or methylene blue. In both combination treatments these drugs were shown to inhibit parasite transmission and also to affect the gametocyte sex ratio, although in opposite directions, with methylene blue proposed to be more active on male gametocytes and primaquine on female gametocytes [34].

The present work aims to review studies on $P$. falciparum gametocyte sex determination, highlighting unanswered questions relevant to better understand consequences of sex ratio changes on the modulation of parasite transmission. ${ }^{1}$

\section{Sex determination in Plasmodium falciparum}

During malaria infection, the parasite is faced with a resource allocation trade-off between investing in asexual proliferation for in-host survival or in sexual differentiation for between-host transmission [11].

The development into a male or a female gametocyte in Plasmodium is not determined by sex chromosomes as a single haploid parasite can generate both sexes [24, 35]. Functional investigations on the mechanism(s) of parasite commitment to sexual differentiation have shown that the expression of the PfAP2-G transcription factor is required for the transcriptional activation in stage I gametocytes of genes encoding early gametocyte specific

\footnotetext{
${ }^{1}$ While this manuscript was in preparation, the topic of this review was covered by an excellent review by Tadesse et al. [103].
}

proteins, such as Pfs16, PfMdv-1/peg3, Pfpeg4 and Pfg27, and for gametocyte production [3, 36-39]. Activation of pfap $2 G$ expression requires the release from epigenetic chromosomal silencing of the pfap $2 G$ locus orchestrated by the interaction of the nuclear proteins PfGDV-1 and HP1 [40, 41]. The first marker of gametocytogenesis in both male and female gametocytes is the expression and export in the red blood cell cytoplasm of the parasite protein $P f$ Gametocyte Exported Protein-5 (PfGEXP5) as early as $14 \mathrm{~h}$ post red blood cells invasion [42]. The observation that the expression of pfGEXP5 is PfAP2-G independent [42] and that a limited gametocyte transcriptional program is also initiated in a natural PfAP2-G mutant parasite line [43] altogether suggest that entry in and/or progression of sexual differentiation may involve additional, PfAP2-G independent, mechanism(s).

Independent investigations on $P$. falciparum commitment to the production of male and female gametocytes indicated that distinct subpopulations of schizonts produce a homogeneous progeny of either all male or all female gametocytes $[44,45]$. This is consistent with previous evidence that individual $P$. falciparum schizonts are alternatively committed to either gametocyte production or to further asexual multiplication [46] and that, in transgenic pfAP2-G-tagged parasites, schizonts are distinguishable for containing either all PfAP2-G positive or all AP2-G negative merozoites [47, 48]. This mechanism of gametocyte sex commitment implies that $P$. falciparum modifies sex ratio by changing the proportion of schizonts committed to male or female gametocyte production. Considering also the long time required for $P$. falciparum gametocytes to be mature for fertilization, parasite sex ratio adjustment in response to any given factor appears to be a slow process, indeed appreciable over long infection times.

To partly correct this picture, recent reports showed in Plasmodium berghei and in P. falciparum that induction or stabilization of AP2-G expression early after merozoite invasion can redirect differentiation of the newly invaded parasite towards becoming a gametocyte [48, 49]. If this modulation also applied to sex determination and occurred in natural infections, this would introduce a slightly higher flexibility in the parasite adaptive mechanism to govern its sex ratio. In any case, the above investigations altogether indicate that the gametocyte sex is determined very early, and possibly at the same time, of the parasite commitment to sexual differentiation.

In $P$. falciparum, the morphological differences between male and female gametocytes appear as early as stage III [50], approximately 4 days post red blood cells invasion. 'Omics' analyses of purified female and male gametocytes marked by specific fluorescent reporters in P. berghei [51] and in P. falciparum [52] showed that 
sexual dimorphism is based on major differences in the transcriptomes and proteomes of the two sexes, which are responsible for the divergent physiology of male and female gametocytes geared to achieve gamete fertilization in the mosquito host and essential for life cycle progression [51, 52]. In P. falciparum, 247 out of 2110 proteins were found to be differently expressed between sexes, 206 in male and 41 in female gametocytes [52]. Proteins expressed exclusively in male gametocytes were mainly annotated as involved in genome replication and formation of eight motile gametes, whereas the female specific proteins were associated with metabolism, translation and organelle functions [51-53].

In some cases, proteins previously described as gametocyte specific were reported to have sex specific roles, such as Pfg377 [54], involved in the production of osmiophilic bodies [55], produced in female gametocytes since the stage III [56], the 6-cysteine domain protein Pfs47, expressed exclusively in female gametocytes from stage II [57], and the gamete surface protein Pfs25 [58], whose transcript has been the first marker used to quantify $P$. falciparum female gametocytes in reverse transcriptase quantitative PCR (qRT-PCR) [59]. This analysis also confirmed the male gametocyte specific expression of the Pfs230 protein, expressed in stages IV-V [60], whose transcript has been used to quantify male gametocytes in RT-PCR assays [59].

On the other hand, proteins expressed in both gametocyte sexes have been proposed to play a sex specific role in male gametocytes, such as Pfs48/45, expressed on the gametocyte surface from stage II [61], whose ablation reduced only male gamete ability to penetrate female gametes [57], or the regulatory protein PfPuf2, whose ablation showed a phenotype only in the differentiation of male gametocytes [62].

Of specific relevance for the ability of male and female gametes to produce and respond to external cues in order to fertilize and to produce a viable diploid mosquito stage, the above 'omics' analyses revealed, both in $P$. berghei and $P$. falciparum, a sex-specific distribution of signaling proteins such as kinases and phosphatases $[51,52]$. Five protein kinases and ten phosphatases were identified as upregulated in P. falciparum female gametocytes, whereas ten kinases and three phosphatases were upregulated in male gametocytes [52]. In P. berghei, two kinases were identified to be female gametocyte specific whereas two kinases and four phosphatases were specific to male gametocytes [51].

\section{Host and parasite factors affecting Plasmodium gametocyte sex ratio}

The female biased sex ratio in Plasmodium parasites [63-65] is intuitively explained as a way to optimize fertilization since a single male gametocyte produces eight flagellated microgametes, a feature particularly important when gametocyte densities become critically low [17]. The gametocyte sex ratio can nevertheless be affected by human as well as parasite factors through mechanisms that still need to be elucidated $[25,45,66]$.

Several investigations proposed a role of human host factors, such as anaemia and immunity $[11,67-70]$ and of parasite factors such as asexual parasite density [4], parasite diversity [71] and competition, as well as the duration of malaria infection [12, 72-74]. Anaemia, a factor associated to malaria, was shown to affect parasite sex allocation not only through increased gametocyte production but also through a more male-biased sex ratio [25, 27], with the erythropoietin (Epo) hormone, an erythropoiesis inductor, being shown in rodent and avian malaria parasites to play a role in the male biased shift of sex ratio [25]. Anaemia was also described to prolong the survival of male gametocytes, favoring malaria transmission [69].

In addition to host factors involved in erythropoiesis and anaemia, the immune response developed against asexual parasites and gametocytes has been proposed to affect sex ratio as the proportion of male gametocytes was reported to increase in prolonged malaria infections [75]. This might be viewed as a parasite evolutionary strategy to increase proportion and total number of the cell type more vulnerable to antibody attack. Indeed, although antibodies against gametocyte surface antigens, acting only after gamete egress from the erythrocyte in the mosquito gut [76, 77], affect both sexes (e.g. by efficiently agglutinating gametes), they are particularly effective against the short lived, motile male gametes [76]. A higher rate of non-synonymous vs synonymous mutations was calculated in the coding sequences of male expressed genes, revealing that male gamete antigens undergo a comparatively faster adaptive evolution than other parasite antigens [78]. This may represent an additional, complementary strategy to protect male gametes from the mounting immune response.

One parasite factor affecting sex ratio is the competition between parasite clones [20, 30, 79]. It has been observed in multiclonal $P$. falciparum infections that each parasite clone produces a more male biased gametocyte population [30], indicating that competition between clones may favor a more even sex ratio, which was interpreted as a way to maximize each clone fertilization efficiency [30, 35, 80]. In human malaria infections, the presence of multiple genotypes may be explained by either subsequent infections or simultaneous acquisition of multiple clones from a single mosquito bite [81]. Understanding how the genetic complexity of co-infecting parasite clones and the subsequent changes in sex allocation strategies may influence parasite infectivity to 
mosquitoes is a major goal to elucidate malaria parasite transmission dynamics.

\section{Gametocyte sex specific susceptibility to antimalarial drugs}

Anti-malarial drug treatments aim to cure malaria infections as rapidly, reliably and safely as possible [82] and are for this reason targeted to hit the asexual pathogenic forms of the parasite. However, anti-malarial drugs, including artemisinin derivatives, are generally less or not at all effective on gametocytes [83-85]. Treatment failure is associated to an increased gametocyte carriage and clinical observations revealed that chloroquine and sulfadoxine-pyrimethamine post treatment gametocytaemia can be considered as an early parasitological indicator of reduced drug sensitivity [19, 86, 87].

In the context of malaria elimination and eradication, the need of targeting gametocytes, in P. falciparum so far attacked only by primaquine, is widely recognized. In vitro assays testing a panel of anti-malarial drugs on $P$. falciparum and $P$. berghei gametocytes indicated that male gametocytes show a higher vulnerability than females to drug treatment [33], leading to suggest the strategy of targeting this minority fraction of more susceptible sexual stages, yet required for fertilization, to efficiently limit malaria parasite transmission [88].

This issue is now being addressed in in vivo settings. Reports evaluating gametocyte clearance by anti-malarial drugs and sex specific densities could not find significant changes in gametocyte sex ratio [30, 89]. On the other hand, two recent clinical trials studied the effect of anti-malarial drugs on gametocyte sex ratio in vivo and concluded that treatments produced in both instances a shift in the gametocyte sex ratio. One clinical trial was conducted in Kenya with 120 infected children from an area of moderate malaria transmission. RT-qPCR assays amplifying the female marker $p f s 25$ and the male marker pfGMET were used to measure the gametocyte sex ratio after a dihydroartemisinin-piperaquine treatment alone or combined with primaquine. In both cases male gametocytes appeared to be cleared more slowly than females, resulting in a male shifted sex ratio [32]. Another clinical trial was conducted in Mali on 80 infected males aged 5 to 55 from a hyperendemic, highly seasonal malarious region. The same assays were used to measure effect on gametocyte sex ratios of the addition of primaquine to a sulfadoxine-pyrimethamine and amodiaquine treatment and of the addition of methylene blue to a dihydroartemisinin-piperaquine treatment. The significant decrease in overall gametocyte density associated in particular to the treatment with methylene blue was in this case associated with a strongly reduced circulation time of male gametocytes and an increased female sex ratio [32, 34].
In this study, effect of the different drug regimens on parasite transmission was assessed by measuring the proportion of mosquitoes that became infected after feeding on blood samples of the trial participants taken before and after 2 and 7 days from treatment. Interestingly, a significant decrease of infection prevalence was observed already after 2 days of the treatments including primaquine and methylene blue, when however gametocyte density (by microscopy) and proportion of male and female gametocytes (by RT-qPCR assays) were not affected. This result, which confirmed previous observations on the activity of primaquine [85] was recently interpreted as an evidence of an early sterilizing effect on gametocytes of the two drugs, whose transmissionblocking effects precede gametocyte clearance [90]. As the latter assays measure density of male and female gametocytes amplifying sex specific transcripts, it is possible that the target mRNAs persist in morphologically detectable, but likely damaged or dead gametocytes, affecting the assay predictability of parasite viability. This suggests that evidences of gametocyte sex specific drug susceptibility have to be object of additional studies and of independent molecular and cell-based assays. This also calls for the urgent need of reliable molecular markers of gametocyte fitness, predictive of mosquito infectiousness, in whose absence xenodiagnosis remains of key importance to assess transmission-blocking properties of anti-malarials.

\section{Development of gametocyte sex specific diagnostic tools and application in investigating sex ratio dynamics}

The identification of gametocyte carriers is important for determining the sources of infection in a community, but gametocyte presence and concentration are not linearly predictive of parasite infectiousness to mosquito. Measuring gametocyte sex ratio may, therefore, provide a different, possibly more predictive, parameter for mosquito infectivity to be used in improved control strategies. Early studies in endemic areas that included gametocyte sex ratio assessments have used laborious microscopy techniques $[69,89]$. However, a critical issue is that identification and counts of male and female gametocytes relied upon inspection of Giemsa stained smears by conventional light microscopy and by sexing gametocytes by the pink or blue color of the cytoplasm of male and female gametocytes, respectively. Obviously, these measurements could be performed only in microscopy positive slides, with densities of at least ten gametocytes/ $\mu \mathrm{l}[14,30]$, and prevented measuring sex ratio in infections with submicroscopic gametocyte carriages [91, 92]. To overcome this problem, in addition to improving the molecular tools to detect parasitaemia and overall gametocytaemia $[81,93]$, methods have been developed in the 
past few years to specifically detect and quantify male and female gametocytes, based on the reverse transcription and polymerase chain reaction (RT-PCR) amplification of gametocyte sex specific transcripts.

The first study was the report by Schneider et al. [59], which used the $p f s 25$ and $p f 230 p$ mRNAs as female and male markers, respectively, to be amplified in $P$. falciparum mature gametocytes. These genes were chosen due to their expression during late stage gametocytes and, as $p f s 25$ shows a limited polymorphism, this marker is currently used to quantify gametocytes from field isolates, also relying on the fact that female gametocytes are generally the more abundant sex $[59,94,95]$. The transcriptomics analysis of purified male and female gametocytes [52] provided additional sex specific transcripts as reagents in improved sex specific q-RT-PCR diagnostic assays. The $p f 13$ (PF3D7_1311100) and the $p f G K$ (PF3D7_1351600) mRNAs were used as male and female gametocyte specific markers in a homogeneous SYBRGreen q-RT-PCR assay, utilized to measure gametocyte sex ratio in epidemiological samples from Burkina Faso [96]. A novel male gametocyte marker, pfMGET (Plasmodium falciparum male gametocyte-enriched transcript, PF3D7_1469900), was also described in a novel gametocyte sex specific RT-PCR assay [32]. To overcome the limitation that separate quantification of male and female gametocytes could bias the reliable determination of sex ratio, a novel multiplex assay was developed, using the above pfMGET mRNA and the female pfCCp4 (PF3D7_0903800) transcript. An important improvement in this assay, besides multiplexing, was that both transcripts are amplified from an intron containing region, which enables quality control of the amplification product and avoids DNAseI sample treatment [97].

\section{The effect of Plasmodium gametocytes sex ratio on malaria parasite transmission}

Gametocyte sex ratio has been shown to be under strong selection pressure both as an adaptive response to a worsening blood environment for transmission and to the number of co-infecting clones in vertebrates [11, 28, 79]. However, the impact of sex ratio dynamics on the transmission success of $P$. falciparum is still far from being fully explained and represents a major challenge in translating sex ratio measurements into prediction of parasite transmissibility.

Some in vitro [98] and in vivo infections [65] studies have shown that a higher male sex ratio was more infectious to mosquitoes. As the gametocyte sex ratio becomes significantly male biased when gametocytes density is low $[64,99,100]$, it is critical to elucidate the functional relationship between sex ratio and gametocytes density. In this respect, the analysis of gametocyte sex ratios and of the resulting mosquito infectivity data from 148 feeding experiments on naturally infected gametocyte carriers in Mali, Burkina Faso and Cameroon importantly showed that male gametocyte presence becomes critically important only at low gametocyte densities [101].

Integrating the information gained in epidemiological studies and clinical trials on microscopy-positive and sub-microscopic gametocyte densities and on gametocyte sex ratios using the recently developed q-RT-PCR techniques will be of key importance to investigate factors affecting malaria transmission at the population level.

\section{Conclusion}

In recent years, the challenge to eliminate malaria focused on the control of malaria parasite transmission and highlighted the gametocytes and their biology as a crucial objects of investigation. The development of molecular tools based on gametocyte sex specific markers is increasingly pairing with novel relevant bioassays for the assessment of gametocyte functionality and viability [102]. Altogether these tools will enable us to understand if and how some anti-malarial drugs differentially affect mature male and female gametocytes in natural infections and in laboratory settings. The main challenge of these assays is to what extent they are and will be able to translate determination of gametocyte numbers into measurements of gametocyte fitness. This will be critical to confidently use gametocyte sex ratio to predict parasite infectiousness to mosquito, with an obvious impact on our ability to implement appropriate and effective measures to block parasite transmission.

\footnotetext{
Abbreviations

RNA: ribonucleic acid; RT-PCR: reverse transcriptase-polymerase chain reaction; PQ: primaquine; PfGDV-1: Plasmodium falciparum gametocyte development 1; PfHP1: Plasmodium falciparum heterochromatin protein 1; PfGK:

Plasmodium falciparum: glycerol kinase; PfMGET: Plasmodium falciparum male gametocyte-enriched transcript; q-RT-PCR: quantitative real time PCR.
}

\section{Authors' contributions}

$\mathrm{NBH}, \mathrm{SI}, \mathrm{GS}, \mathrm{SBS}$ and PA, designed, wrote the first draft the manuscript and review the final version; SSS, SS, AD, GS, SN'F, AST, contributed in reviewing the final version of the manuscript. All the authors read and approved the final version. SI and PA co-supervised as corresponding authors the writing of the manuscript. All authors read and approved the final manuscript.

\section{Author details \\ ${ }^{1}$ Centre National de Recherche et de Formation sur le Paludisme, Ouagadou- gou, Burkina Faso. ${ }^{2}$ Dipartimento di Malattie Infettive, Istituto Superiore di Sanità, Rome, Italy. ${ }^{3}$ University Joseph Ki Zerbo, Ouagadougou, Burkina Faso. ${ }^{4}$ Groupe de Recherche Action Santé, Ouagadougou, Burkina Faso.}

\section{Competing interests}

The authors declare that they have no competing interests. 


\section{Availability of data and materials \\ Not applicable.}

\section{Consent for publication}

Not applicable.

\section{Ethics approval and consent to participate}

Not applicable.

\section{Funding}

Collaboration visits to the Italian Malaria Institutions was supported by the Italian Cooperation in Burkina Faso. In ISS, G. S. and the research on P. falciparum transmission blocking drugs in P. A.'s laboratory are presently supported by a "Progetto di Grande Rilevanza" of the Italian Ministry of Foreign Affairs and International Cooperation and Ministry of Health and by Istituto Superiore di Sanità

\section{Publisher's Note}

Springer Nature remains neutral with regard to jurisdictional claims in published maps and institutional affiliations.

Received: 19 December 2018 Accepted: 5 March 2019

Published online: 12 March 2019

\section{References}

1. WHO. World malaria report 2017. Geneva: World Health Organization; 2017

2. Programme RBM. The global malaria action plan for a malaria free world. Geneva: World Health Organization; 2008.

3. Baker DA. Malaria gametocytogenesis. Mol Biochem Parasitol. 2010;172:57-65.

4. Boudin C, Robert V. Plasmodium falciparum: épidiométrie de la transmission homme-moustique et de l'infection chez le vecteur. Bull Soc Pathol Exot. 2003;96:335-40.

5. Hawking F, Wilson ME, Gammage K. Evidence for cyclic development and short-lived maturity in the gametocytes of Plasmodium falciparum. Trans R Soc Trop Med Hyg. 1971;65:549-59.

6. Smalley ME, Abdalla S, Brown J. The distribution of Plasmodium falciparum in the peripheral blood and bone marrow of Gambian children. Trans R Soc Trop Med Hyg. 1981;75:103-5.

7. Smalley ME, Sinden RE. Plasmodium falciparum gametocytes: their longevity and infectivity. Parasitology. 1977;74:1-8.

8. Robert V, Boudin C. Biologie de la transmission homme-moustique du Plasmodium. Bull Soc Pathol Exot. 2003;96:6-20.

9. Lensen A, Bril A, van de Vegte M, van Gemert GJ, Eling W, Sauerwein R. Plasmodium falciparum: infectivity of cultured, synchronized gametocytes to mosquitoes. Exp Parasitol. 1999;91:101-3.

10. Kuehn A, Pradel G. The coming-out of malaria gametocytes. J Biomed Biotechnol. 2010;2010:976827.

11. Carter LM, Kafsack BFC, Llinós M, Mideo N, Pollitt LC, Reece SE. Stress and sex in malaria parasites: why does commitment vary? Evol Med Public Health. 2013;2013:135-47.

12. Price R, Nosten F, Simpson JA, Luxemburger C, Phaipun L, ter Kuile F, et al. Risk factors for gametocyte carriage in uncomplicated falciparum malaria. Am J Trop Med Hyg. 1999;60:1019-23.

13. Drakeley CJ, Secka I, Correa S, Greenwood BM, Targett GA. Host haematological factors influencing the transmission of Plasmodium falciparum gametocytes to Anopheles gambiae s.s. mosquitoes. Trop Med Int Health. 1999;4:131-8.

14. Gbotosho GO, Sowunmi A, Okuboyejo TM, Happi CT, Michael OS, Folarin OA, et al. Plasmodium falciparum gametocyte carriage, emergence, clearance and population sex ratios in anaemic and non-anaemic malarious children. Mem Inst Oswaldo Cruz. 2011;106:562-9.

15. Buckling A, Read AF. The effect of partial host immunity on the transmission of malaria parasites. Proc Biol Sci. 2001;268:2325-30.
16. Ono T, Nakai T, Nakabayashi T. Induction of gametocytogenesis in Plasmodium falciparum by the culture supernatant of hybridoma cells producing anti-P. falciparum antibody. Biken J. 1986;29:77-81.

17. Talman AM, Paul RE, Sokhna CS, Domarle O, Ariey F, Trape JF, Robert V. Influence of chemotherapy on the Plasmodium gametocyte sex ratio of mice and humans. Am J Trop Med Hyg. 2004;71:739-44.

18. Sowunmi A, Fateye BA. Plasmodium falciparum gametocytaemia in Nigerian children: before, during and after treatment with antimalarial drugs. Trop Med Int Health. 2003;8:783-92.

19. Peatey CL, Skinner-Adams TS, Dixon MW, McCarthy JS, Gardiner DL, Trenholme KR. Effect of antimalarial drugs on Plasmodium falciparum gametocytes. J Infect Dis. 2009;200:1518-21.

20. Vardo-Zalik AM, Schall JJ. Clonal diversity alters the infection dynamics of a malaria parasite (Plasmodium mexicanum) in its vertebrate host. Ecology. 2009;90:29-36.

21. Bousema JT, Drakeley CJ, Mens PF, Arens T, Houben R, Omar SA, et al. Increased Plasmodium falciparum gametocyte production in mixed infections with P. malariae. Am J Trop Med Hyg. 2008;78:442-8.

22. McKenzie FE, Jeffery GM, Collins WE. Plasmodium malariae infection boosts Plasmodium falciparum gametocyte production. Am J Trop Med Hyg. 2002;67:411-4.

23. Ouedraogo AL, Schneider P, de Kruijf M, Nebie I, Verhave JP, CuzinOuattara N, et al. Age-dependent distribution of Plasmodium falciparum gametocytes quantified by Pfs 25 real-time QT-NASBA in a cross-sectional study in Burkina Faso. Am J Trop Med Hyg. 2007;76:626-30.

24. Carter R, Graves PM. Gametpcytes. In: Wernsdorfer WH, McGregor IA, editors. Malaria principles and practice of malariology, vol. 1. Churchill Livingstone: Edinburgh; 1988. p. 253-306.

25. Paul RE, Coulson TN, Raibaud A, Brey PT. Sex determination in malaria parasites. Science. 2000;287:128-31.

26. Carter LM, Schneider P, Reece SE. Information use and plasticity in the reproductive decisions of malaria parasites. Malar J. 2014;13:115-26.

27. Reece SE, Duncan AB, West SA, Read AF. Host cell preference and variable transmission strategies in malaria parasites. Proc Biol Sci. 2005;272:511-7.

28. Paul RE, Brey PT, Robert V. Plasmodium sex determination and transmission to mosquitoes. Trends Parasitol. 2002;18:32-8.

29. Robert V, Sokhna CS, Rogier C, Ariey F, Trape JF. Sex ratio of Plasmodium falciparum gametocytes in inhabitants of Dielmo, Senegal. Parasitology. 2003;127:1-8

30. Sowunmi A, Gbotosho GO, Happi CT, Folarin OA, Balogun ST. Population structure of Plasmodium falciparum gametocyte sex ratios in malarious children in an endemic area. Parasitol Int. 2009;58:438-43.

31. Sowunmi A, Balogun T, Gbotosho GO, Happi CT, Adedeji AA, Bolaji OM, et al. Activities of artemether-lumefantrine and amodiaquine-sulfalenepyrimethamine against sexual-stage parasites in falciparum malaria in children. Chemotherapy. 2008;54:201-8.

32. Stone W, Sawa P, Lanke K, Rijpma S, Oriango R, Nyaurah M, et al. A molecular assay to quantify male and female Plasmodium falciparum gametocytes: results from 2 randomized controlled trials using primaquine for gametocyte clearance. J Infect Dis. 2017:216:457-67.

33. Delves MJ, Ruecker A, Straschil U, Lelievre J, Marques S, Lopez-Barragan $\mathrm{MJ}$, et al. Male and female Plasmodium falciparum mature gametocytes show different responses to antimalarial drugs. Antimicrob Agents Chemother. 2013;57:3268-74.

34. Dicko A, Roh ME, Diawara H, Mahamar A, Soumare HM, Lanke K, et al. Efficacy and safety of primaquine and methylene blue for prevention of Plasmodium falciparum transmission in Mali: a phase 2, single-blind randomised controlled trial. Lancet Infect Dis. 2018;18:627-39.

35. Paul RE, Brey PT, Robert V. Plasmodium sex determination and transmission to mosquitoes. Trends Parasitol. 2002;18:32-8.

36. Sharma A, Sharma I, Kogkasuriyachai D, Kumar N. Structure of a gametocyte protein essential for sexual development in Plasmodium falciparum. Nat Struct Biol. 2003:10:197-203.

37. Carter R, Graves P, Creasey A, Byrne K, Read D, Alano P, et al. Plasmodium falciparum: an abundant stage-specific protein expressed during early gametocyte development. Exp Parasitol. 1989;69:140-9.

38. Alano P. Plasmodium falciparum gametocytes: still many secrets of a hidden life. Mol Microbiol. 2007:66:291-2.

39. Lobo CA, Konings RNH, Kumar N. Expression of early gametocytestage antigens Pfg27 and Pfs16 in synchronized gametocytes and 
non-gametocyte producing clones of Plasmodium falciparum. Mol Biochem Parasitol. 1994;68:151-4.

40. Filarsky M, Fraschka SA, Niederwieser I, Brancucci NMB, Carrington E, Carrio E, et al. GDV1 induces sexual commitment of malaria parasites by antagonizing HP1-dependent gene silencing. Science. 2018;359:1259-63.

41. Brancucci NMB, Bertschi NL, Zhu L, Niederwieser I, Chin WH, Wampfler $\mathrm{R}$, et al. Heterochromatin protein 1 secures survival and transmission of malaria parasites. Cell Host Microbe. 2014;16:165-76.

42. Tiburcio M, Dixon MW, Looker O, Younis SY, Tilley L, Alano P. Specific expression and export of the Plasmodium falciparum Gametocyte EXported Protein-5 marks the gametocyte ring stage. Malar J. 2015:14:334.

43. Painter HJ, Carrasquilla M, Llinas M. Capturing in vivo RNA transcriptional dynamics from the malaria parasite Plasmodium falciparum. Genome Res. 2017;27:1074-86.

44. Silvestrini F, Alano P, Williams JL. Commitment to the production of male and female gametocytes in the human malaria parasite Plasmodium falciparum. Parasitology. 2000;121:465-71.

45. Smith TG, Lourenco P, Carter R, Walliker D, Ranford-Cartwright LC. Commitment to sexual differentiation in the human malaria parasite, Plasmodium falciparum. Parasitology. 2000;121:127-33.

46. Bruce MC, Baker DA, Alano P, Rogers NC, Graves PM, Targett GA, Carter R. Sequence coding for a sexual stage specific protein of Plasmodium falciparum. Nucleic Acids Res. 1990;18:3637.

47. Kafsack BF, Rovira-Graells N, Clark TG, Bancells C, Crowley VM, Campino $\mathrm{SG}$, et al. A transcriptional switch underlies commitment to sexual development in malaria parasites. Nature. 2014;507:248-52.

48. Bancells C, Llora-Batlle O, Poran A, Notzel C, Rovira-Graells N, Elemento $\mathrm{O}$, et al. Revisiting the initial steps of sexual development in the malaria parasite Plasmodium falciparum. Nat Microbiol. 2019:4:144-54.

49. Kent RS, Modrzynska KK, Cameron R, Philip N, Billker O, Waters AP. Inducible developmental reprogramming redefines commitment to sexual development in the malaria parasite Plasmodium berghei. Nat Microbiol. 2018:3:1206-13.

50. Sinden RE. Sexual development of malaria parasites. Adv Parasitol. 1983;22:153-216.

51. Khan SM, Franke-Fayard B, Mair GR, Lasonder E, Janse CJ, Mann M, et al. Proteome analysis of separated male and female gametocytes reveals novel sex-specific Plasmodium biology. Cell. 2005;121:675-87.

52. Lasonder E, Rijpma SR, van Schaijk BCL, Hoeijmakers WAM, Kensche PR, Gresnigt MS, et al. Integrated transcriptomic and proteomic analyses of P. falciparum gametocytes: molecular insight into sex-specific processes and translational repression. Nucleic Acids Res. 2016;44:6087-101.

53. Miao J, Chen Z, Wang Z, Shrestha S, Li X, Li R, Cui L. Sex-specific biology of the human malaria parasite revealed from the proteomes of mature male and female gametocytes. Mol Cell Proteomics. 2017;16:537-51.

54. Alano P, Read D, Bruce M, Aikawa M, Kaido T, Tegoshi T, et al. COS cell expression cloning of Pfg377, a Plasmodium falciparum gametocyte antigen associated with osmiophilic bodies. Mol Biochem Parasitol. 1995:74:143-56.

55. de Koning-Ward TF, Olivieri A, Bertuccini L, Hood A, Silvestrini F, Charvalias K, et al. The role of osmiophilic bodies and Pfg377 expression in female gametocyte emergence and mosquito infectivity in the human malaria parasite Plasmodium falciparum. Mol Microbiol. 2008:67:278-90.

56. Severini C, Silvestrini F, Sannella A, Barca S, Gradoni L, Alano P. The production of the osmiophilic body protein Pfg377 is associated with stage of maturation and sex in Plasmodium falciparum gametocytes. Mol Biochem Parasitol. 1999;100:247-52.

57. van Schaijk BCL, van Dijk MR, van de Vegte-Bolmer M, van Gemert G-J, van Dooren MW, Eksi S, et al. Pfs47, paralog of the male fertility factor Pfs $48 / 45$, is a female specific surface protein in Plasmodium falciparum. Mol Biochem Parasitol. 2006;149:216-22.

58. Vermeulen AN, van Deursen J, Brakenhoff RH, Lensen TH, Ponnudurai T, Meuwissen JH. Characterization of Plasmodium falciparum sexual stage antigens and their biosynthesis in synchronised gametocyte cultures. Mol Biochem Parasitol. 1986;20:155-63.

59. Schneider P, Reece SE, van Schaijk BC, Bousema T, Lanke KH, Meaden CS, et al. Quantification of female and male Plasmodium falciparum gametocytes by reverse transcriptase quantitative PCR. Mol Biochem Parasitol. 2015:199:29-33.
60. Eksi S, Williamson KC. Male-specific expression of the paralog of malaria transmission-blocking target antigen Pfs230, PfB0400w. Mol Biochem Parasitol. 2002;122:127-30.

61. Lobo CA, Fujioka H, Aikawa M, Kumar N. Disruption of the Pfg27 locus by homologous recombination leads to loss of the sexual phenotype in P. falciparum. Mol Cell. 1999:3:793-8.

62. Miao J, Li J, Fan Q, Li X, Cui L. The Puf-family RNA-binding protein PfPuf2 regulates sexual development and sex differentiation in the malaria parasite Plasmodium falciparum. J Cell Sci. 2010;123:1039-49.

63. Schall JJ. The sex ratio of Plasmodium gametocytes. Parasitology. 1989;98:343-50.

64. Paul RE, Brockman A, Price RN, Luxemburger C, White NJ, Looareesuwan $\mathrm{S}$, et al. Genetic analysis of Plasmodium falciparum infections on the north-western border of Thailand. Trans R Soc Trop Med Hyg. 1999:93:587-93.

65. Robert V, Read AF, Essong J, Tchuinkam T, Mulder B, Verhave JP, et al. Effect of gametocyte sex ratio on infectivity of Plasmodium falciparum to Anopheles gambiae. Trans R Soc Trop Med Hyg. 1996:90:621-4.

66. Talman AM, Paul RE, Sokhna CS, Domarle O, Ariey F, Trape JF, et al. Influence of chemotherapy on the Plasmodium gametocyte sex ratio of mice and humans. Am J Trop Med Hyg. 2004;71:739-44.

67. Bousema T, Drakeley C. Epidemiology and infectivity of Plasmodium falciparum and Plasmodium vivax gametocytes in relation to malaria control and elimination. Clin Microbiol Rev. 2011;24:377-410.

68. Eksi S, Morahan BJ, Haile Y, Furuya T, Jiang H, Ali O, et al. Plasmodium falciparum gametocyte development 1 (Pfgdv1) and gametocytogenesis early gene identification and commitment to sexual development. PLoS Pathog. 2012;8:e1002964.

69. Sowunmi A, Balogun ST, Gbotosho GO, Happi CT. Plasmodium falciparum gametocyte sex ratios in children with acute, symptomatic, uncomplicated infections treated with amodiaquine. Malar J. 2008;7:169.

70. Sowunmi A, Balogun ST, Gbotosho GO, Happi CT. Influence of anemia on Plasmodium falciparum gametocyte sex ratios in acutely symptomatic children. Open Trop Med J. 2008;1:13-20.

71. Bousema JT, Drakeley CJ, Mens PF, Arens T, Houben R, Omar SA, et al. Increased Plasmodium falciparum gametocyte production in mixed infections with P. malariae. Am J Trop Med Hyg. 2008;78:442-8.

72. Sowunmi A, Fateye BA, Adedeji AA, Fehintola FA, Happi TC. Risk factors for gametocyte carriage in uncomplicated falciparum malaria in children. Parasitology. 2004;129:255-62.

73. White NJ. Malaria parasite clearance. Malar J. 2017:16:88-102

74. Sokhna CS, Trape JF, Robert V. Gametocytaemia in Senegalese children with uncomplicated falciparum malaria treated with chloroquine, amodiaquine or sulfadoxine + pyrimethamine. Parasite. 2001;8:243-50.

75. Sowunmi A, Balogun ST, Gbotosho GO, Happi CT. Plasmodium falciparum gametocyte sex ratios in symptomatic children treated with antimalarial drugs. Acta Trop. 2009;109:108-17.

76. Rener J, Carter R, Rosenberg Y, Miller LH. Anti-gamete monoclonal antibodies synergistically block transmission of malaria by preventing fertilization in the mosquito. Proc Natl Acad Sci USA. 1980;77:6797-9.

77. Carter R, Gwadz RW, Green I. Plasmodium gallinaceum: transmissionblocking immunity in chickens. II. The effect of antigamete antibodies in vitro and in vivo and their elaboration during infection. Exp Parasitol. 1979:47:194-208.

78. Khan SM, Reece SE, Waters AP, Janse CJ, Kaczanowski S. Why are male malaria parasites in such a rush? Sex-specific evolution and host-parasite interactions. Evol Med Public Health. 2013;2013:3-13.

79. Reece SE, Drew DR, Gardner A. Sex ratio adjustment and kin discrimination in malaria parasites. Nature. 2008:453:609-14.

80. Read AF, Anwar M, Shutler D, Nee S. Sex allocation and population structure in malaria and related parasitic protozoa. Proc Biol Sci. 1995;260:359-63.

81. Babiker HA, Schneider P, Reece SE. Gametocytes: insights gained during a decade of molecular monitoring. Trends Parasitol. 2008;24:525-30.

82. WHO. Guidelines for the treatment of malaria. 2nd ed. Geneva: World Health Organization; 2010.

83. Drakeley CJ, Jawara M, Targett GA, Walraven G, Obisike U, Coleman R, et al. Addition of artesunate to chloroquine for treatment of Plasmodium falciparum malaria in Gambian children causes a significant but 
short-lived reduction in infectiousness for mosquitoes. Trop Med Int Health. 2004;9:53-61.

84. Okell LC, Drakeley CJ, Ghani AC, Bousema T, Sutherland CJ. Reduction of transmission from malaria patients by artemisinin combination therapies: a pooled analysis of six randomized trials. Malar J. 2008;7:125-38.

85. White NJ, Ashley EA, Recht J, Delves MJ, Ruecker A, Smithuis FM, et al. Assessment of therapeutic responses to gametocytocidal drugs in Plasmodium falciparum malaria. Malar J. 2014;13:483.

86. Hallett RL, Dunyo S, Ord R, Jawara M, Pinder M, Randall A, et al. Chloroquine/sulphadoxine-pyrimethamine for gambian children with malaria: transmission to mosquitoes of multidrug-resistant Plasmodium falciparum. PLoS Clin Trials. 2006;1:e15.

87. Barnes KI, Little F, Mabuza A, Mngomezulu N, Govere J, Durrheim D, et al. Increased gametocytemia after treatment: an early parasitological indicator of emerging sulfadoxine-pyrimethamine resistance in falciparum malaria. J Infect Dis. 2008;197:1605-13.

88. Mitri C, Thiery I, Bourgouin C, Paul RE. Density-dependent impact of the human malaria parasite Plasmodium falciparum gametocyte sex ratio on mosquito infection rates. Proc Biol Sci. 2009;276:3721-6.

89. Gbotosho GO, Sowunmi A, Happi CT. Kinetics of Plasmodium falciparum gametocyte sex ratios: application to the evaluation of the potential of antimalarial drugs to influence malaria transmission. Open Trop Med J. 2011:4:33-8.

90. Bradley J, Soumare HM, Mahamar A, Diawara H, Roh M, Delves M, et al. Transmission-blocking effects of primaquine and methylene blue suggest $P$. falciparum gametocyte sterilisation rather than effects on sex ratio. Clin Infect Dis. 2019:1:1. https://doi.org/10.1093/cid/ciz134.

91. Ouédraogo AL, Bousema T, Schneider P, de Vlas SJ, Ilboudo-Sanogo E, Cuzin-Ouattara N, et al. Substantial contribution of submicroscopical Plasmodium falciparum gametocyte carriage to the infectious reservoir in an area of seasonal transmission. PLoS ONE. 2009:4:e8410.

92. Okell LC, Ghani AC, Lyons E, Drakeley CJ. Submicroscopic infection in Plasmodium falciparum-endemic populations: a systematic review and meta-analysis. J Infect Dis. 2009;200:1509-17.

93. Menegon M, Severini C, Sannella A, Paglia MG, Sangare D, AbdelWahab A, et al. Genotyping of Plasmodium falciparum gametocytes by reverse transcriptase polymerase chain reaction. Mol Biochem Parasitol. 2000;111:153-61.

94. Eksi S, Suri A, Williamson KC. Sex- and stage-specific reporter gene expression in Plasmodium falciparum. Mol Biochem Parasitol. 2008;160:148-51.

95. Kaslow DC, Syin C, McCutchan TF, Miller LH. Comparison of the primary structure of the $25 \mathrm{kDa}$ ookinete surface antigens of Plasmodium falciparum and Plasmodium gallinaceum reveal six conserved regions. Mol Biochem Parasitol. 1989;33:283-7.

96. Santolamazza F, Avellino P, Siciliano G, Yao FA, Lombardo F, Ouedraogo $\mathrm{JB}$, et al. Detection of Plasmodium falciparum male and female gametocytes and determination of parasite sex ratio in human endemic populations by novel, cheap and robust RTqPCR assays. Malar J. 2017;16:468.

97. Meerstein-Kessel L, Andolina C, Carrio E, Mahamar A, Sawa P, Diawara $\mathrm{H}$, et al. A multiplex assay for the sensitive detection and quantification of male and female Plasmodium falciparum gametocytes. Malar J. 2018;17:441-52.

98. Burkot TR, Williams JL, Schneider I. Infectivity to mosquitoes of Plasmodium falciparum clones grown in vitro from the same isolate. Trans $\mathrm{R}$ Soc Trop Med Hyg. 1984;78:339-41.

99. West SA, Smith TG, Nee S, Read AF. Fertility insurance and the sex ratios of malaria and related hemospororin blood parasites. J Parasitol. 2002;88:258-63.

100. Gardner A, Reece SE, West SA. Even more extreme fertility insurance and the sex ratios of protozoan blood parasites. J Theor Biol. 2003;223:515-21.

101. Bradley J, Stone W, Da DF, Morlais I, Dicko A, Cohuet A, et al. Predicting the likelihood and intensity of mosquito infection from sex specific Plasmodium falciparum gametocyte density. Elife. 2018;7:e34463.

102. Birkholtz LM, Coetzer TL, Mancama D, Leroy D, Alano P. Discovering new transmission-blocking antimalarial compounds: challenges and opportunities. Trends Parasitol. 2016;32:669-81.

103. Tadesse FG, Meerstein-Kessel L, Goncalves BP, Drakeley C, Ranford-Cartwright L, Bousema T. Gametocyte sex ratio: the key to understanding Plasmodium falciparum transmission? Trends Parasitol. 2019;35:226-38.
Ready to submit your research? Choose BMC and benefit from:

- fast, convenient online submission

- thorough peer review by experienced researchers in your field

- rapid publication on acceptance

- support for research data, including large and complex data types

- gold Open Access which fosters wider collaboration and increased citations

- maximum visibility for your research: over $100 \mathrm{M}$ website views per year

At BMC, research is always in progress.

Learn more biomedcentral.com/submissions 